\title{
A Study on Assessing a Business Viability for Transition to a Circular Economy
}

\author{
Sugam Upadhayay, Omaima Alqassimi
}

\section{ABSTRACT}

The shift from the existing linear model of the economy to a circular model is gaining traction across business entities, nationally and globally. Minimal studies have been done that would support the circular transition for a business from an existing linear model. There is a significant gap between the formulation and implementation of circular strategies in business. This literature review explores the preexisting concepts of the business model canvas (BMC) and Value Hill tool for the implementation of circular strategies in a business by determining a Good Point for Transition (GPT). The favorable condition, where a business can transition from a linear economy (LE) to a circular economy (CE) is defined as a GPT. This study suggests a three-step generic process that would provide a company with clarity on how to incorporate circular strategies into their structure. Firstly, this review paper defines and elaborates upon the business model canvas (BMC) based on the prior work of Osterwalder and Pigneur (2010) and Lewandowski (2016). Secondly, it analyzes the Value Hill diagram, a strategic tool for circular activities that a business can use upon implementation of a circular model (Achterberg et al., 2016). Finally, this work will indicate how a circular strategy can be selected on the basis of assessment of the BMC and Value Hill diagram of a business. For a better understanding of the process, IKEA's initiatives for circular strategies are used in the study. The paper concludes with a three-step generic model for determining GPT and emphasizes that the adoption of circular strategies for companies depends upon the circular expertise and resources they and their value chain partners have across the Value Hill diagram.

Keywords: circular economy, circular strategies, circular business model canvas, value hill diagram, circular transitions 


\section{Assessing Business Viability for Transition to a Circular Economy}

An alarming pressure on resources has necessitated business entities to rethink their contemporary model of production and consumption (P\&C). Most business entities follow the linear model of $P \& C$, which operates in the take-make-dispose modality. In contrast, excessive pressure on resources for $\mathrm{P} \& \mathrm{C}$ has mandated a transition from this traditional linear economy (LE) model to a circular economy (CE) model, which focuses on a take-make-reuse modality. The transition from LE to CE is crucial; at the same time, it might not be easy for business entities to diversify from their existing linear model to a circular model as it requires resources and circular expertise (Lacy et al., 2020).

Amidst heightening voraciousness for resource consumption, for the first time, the global economy has topped the annual resources requirement of 100 billion tonnes based on the Circular Economy (2020) report. The same report concludes that only 8.6 percent of the world is exhibiting a circular modality. This highlights how fragile and mediocre our supply chain system is when it comes to incorporating a sustainable approach of $\mathrm{P} \& C$. Moving from the more common linear approach to the circular path of $P \& C$ is a necessity for achieving sustainability. CE focuses on enhancing the value of the material (EMF, 2015a), and thus, leads to a reduction on the business footprint and resources required for P\&C. But still, a plethora of confusion exists within the business industry regarding how to transition from a linear to a circular model of $P \& C$.

GPT is defined as the favorable conditions required to move from the linear to the circular model of P\&C. Companies should consider if the transition is economically beneficial to them or not as well as if they have enough resources to transition. But poignantly, comparative research conducted by Upadhayay and Alqassimi (2019) between Nepal and the USA, concluded that less than five percent of the respondents classified themselves as being an expert in terms of understanding the circular economy. The same research found that most of the respondents thought CE was related to waste management, neglecting the higher utilization of
CE for resource management and sustainability. Kirchherr et al. (2017) defines CE as:

A circular economy describes an economic system that is based on business models which replace the 'end-of-life' concept with reducing, alternatively reusing, recycling and recovering materials in production/distribution and consumption processes, thus operating at the micro level (products, companies, consumers), meso level (eco-industrial parks) and macro level (city, region, nation and beyond), with the aim to accomplish sustainable development, which implies creating environment quality, economic prosperity and social equity, to the benefit of current and future generations. (pp. 224-225)

Despite the fact that the European Parliament (2018) has highlighted the positive impact CE could have on the economy, environment, and society, there is still no precise cutoff point to state the best conditions or process for the transition from the LE to CE. This review paper intends to address the gap in research to suggest the steps businesses can take to transition to the circular economy.

\section{Necessity for the Research}

Each business entity is unique in terms of resources, expertise and capacities which may influence their ability to incorporate a circular vision. This study will help businesses to identify appropriate conditions for circular transition along with the selections of effective circular strategies. This study will offer consideration of critical questions like when, how, and where to transition from LE to CE, and ultimately, remove the gap that has been prevalent between the formulation and implementation of circular modality at the business level.

\section{Methods and Materials}

This paper consists of an in-depth literature review to determine the GPT through the analysis of preexisting scholarly articles authored by academics, think-tank organizations, business entities, and governments across the globe. For this purpose, both peer-reviewed as well as non-peer-reviewed papers were analyzed. The decision of including various literature sources was due to the fact that, despite 
the growing requirement of $\mathrm{CE}$ principles for business and sustainability, the academic domains still lack enough literature related to $C E$ (Murray et al., 2017). The lack of peer-reviewed articles and availability of significant seminal work from businesses necessitated the incorporation of non-peer-reviewed papers (Ghisellini et al., 2016; Kirchherr et al., 2017; Schut et al., 2015), which are of great value for this particular literature review article. This research combines the concepts of BMC and Value Hill to strategize a circular option for a business. GPT supports businesses in enhancing the mastery of CE by reconciling existing business models with circular principles, and ultimately, laying out circular strategies a company could incorporate based on technical and non-technical resources available. A three-step process was suggested in this study for a business to use in order to determine its current state of circular resources and to develop appropriate circular strategies to support a circular vision. The first step in this proposed process would be for a business to analyze their existing model based on the BMC (Osterwalder \& Pigneur, 2010), and the circular business model canvas as put forth by Lewandowski (2016). In second step of the process, the outcome from the first step is then viewed through the Value Hill strategic tool to determine circular model strategies (Achterberg et al., 2016). In the last step, a circular strategy decision would need to be made by a business based on the identified gap and opportunities indicated through the BMC and the Value Hill diagram.

\section{Discussion}

\section{Business Model Canvas and Its Components}

A business model is a manifesto which depicts the modality for business operations and its continuity. For a strong understanding of a business model, a compelling business model canvas should be used. A business model canvas defines the organizational value creation, delivery, and capturing strategy (Osterwalder \& Pigneur, 2010). Effective analysis and

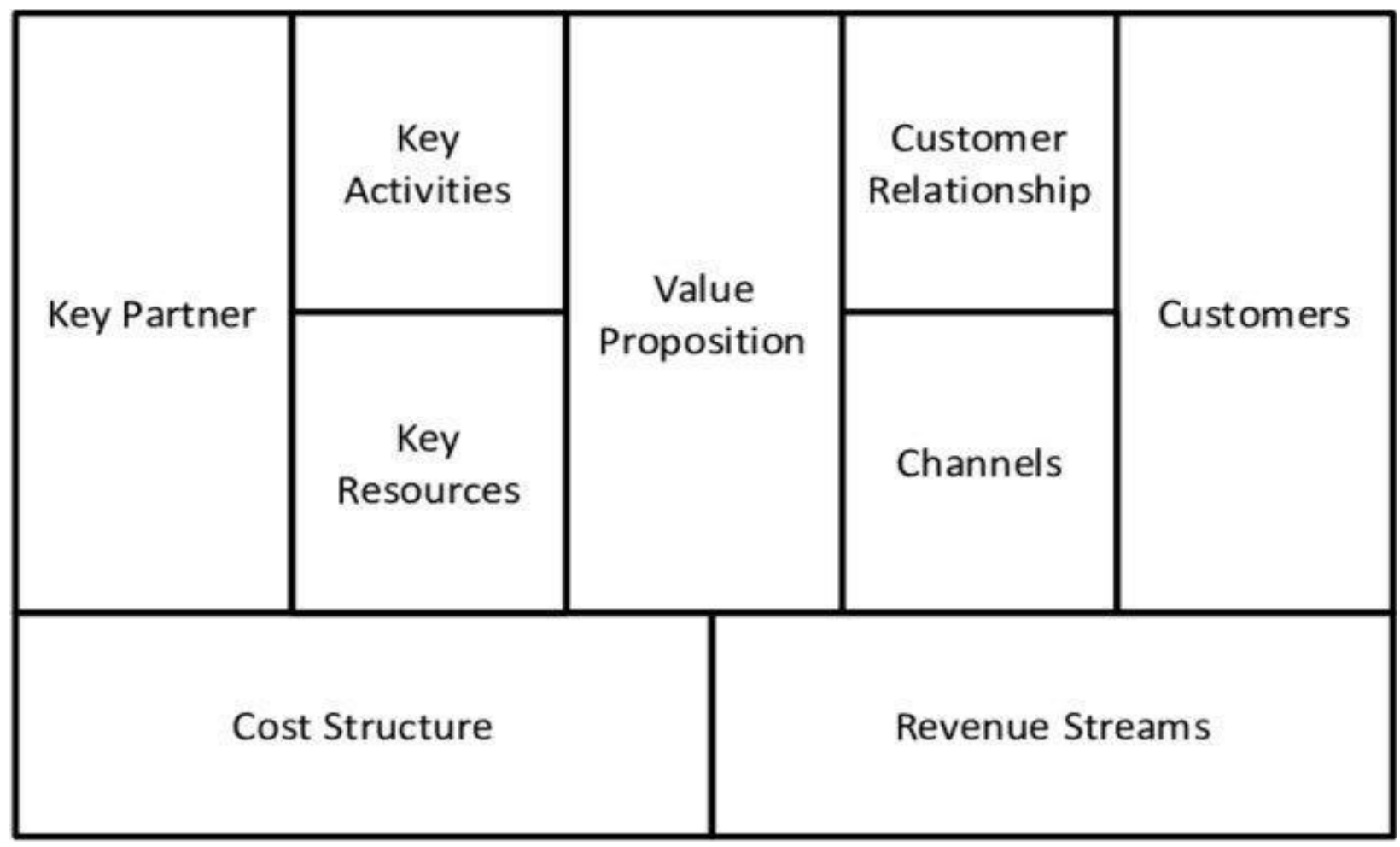

Figure 1. Business Model Canvas with its Components.

Note: Source Osterwalder and Pigneur (2010). This figure demonstrates nine key segments of business model canvas. 


\begin{tabular}{|c|c|c|c|c|}
\hline \multirow[t]{3}{*}{$\begin{array}{l}\text { Parmers } \\
\text { - Cooperitive } \\
\text { thetwotks } \\
\text { Types of } \\
\text { collaboration }\end{array}$} & $\begin{array}{l}\text { Acwihies } \\
\text { - Optumstng performanes } \\
\text { - Product Desigi } \\
\text { - Tobbying } \\
\text { - Remasufactunag } \\
\text { recycling } \\
\text { - Technology exchange }\end{array}$ & \multirow[t]{3}{*}{ 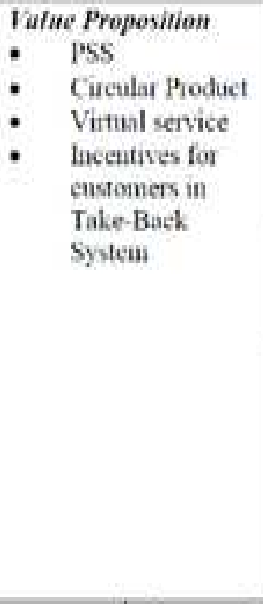 } & 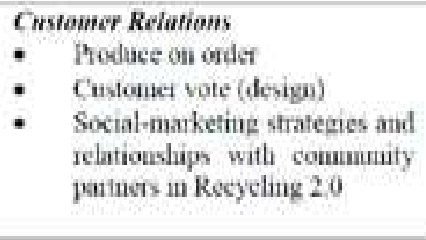 & $\begin{array}{l}\text { Customer } \\
\text { Sigments } \\
\text { Custoner } \\
\text { Iypes }\end{array}$ \\
\hline & \multirow{2}{*}{$\begin{array}{l}\text { Key Resonrces } \\
\text { - Better-performing } \\
\text { materials } \\
\text { - Regencration and } \\
\text { restoring of natural } \\
\text { capital } \\
\text { - Vimalization of } \\
\text { materials } \\
\text { Retrieved Resources } \\
\text { (products, components, } \\
\text { materials) }\end{array}$} & & $\begin{array}{l}\text { Channeds } \\
\text { - Virtualization }\end{array}$ & \\
\hline & & & $\begin{array}{l}\text { Take-Back Systom } \\
\text { - Thke-back management } \\
\text { - Chamnels } \\
\text { - Customer todations }\end{array}$ & \\
\hline \multicolumn{2}{|c|}{$\begin{array}{l}\text { Cost Stricture } \\
\text { - Evaluation criteria } \\
\text { - Value of incentaves for customers } \\
\text { - Guidelines to accoum the conts of uateral flow }\end{array}$} & \multicolumn{2}{|c|}{$\begin{array}{l}\text { Revenue Strcams } \\
\text { - laput-based } \\
\text { - Availability-based } \\
\text { - Usage-based } \\
\text { - Performance-based } \\
\text { - Value of retrieved resources }\end{array}$} & \\
\hline \multicolumn{5}{|l|}{ Adeption Factors } \\
\hline
\end{tabular}

Figure 2. Circular Business Model Canvas.

Note: Adapted from Lewandowski (2016). This figure comprises of eleven major segments in comparison to general BMC as illustrated in Figure 1 which contains nine segments.

understanding of these value-creating segments will help a business to fit well with the circular strategies. These components are interlinked and interdependent upon each other. As illustrated in Figure 1, BMC consists of nine building blocks interrelated; they include: customer segment, value proportion, channel, customer relationship, revenue stream, key resources, key activities, key partnership, and cost structure (Osterwalder \& Pigneur, 2010).

As shown in Figure 1, businesses should have clarity in terms of business partners, core activities, and the resources required to generate value for its customer segment. Simultaneously, a palpable understanding of its customers, relationship with them, and channels used to deliver a product is needed. Thus, a business should perform a cost-benefit analysis to determine its prospects. Moreover, knowing one's own business model will help the company determine the status of resource availability, customer or market awareness, and financial feasibility before initiating circular modalities. Bianchini et al. (2019) asserted that BMC should be easy to understand, replicate real situations, fully depict circular initiatives, quantify the circular initiatives, and focus on maintenance as a stage of the product lifecycle. The BMC helps develop business plans (Ching \& Fauvel, 2013), and the $\mathrm{BMC}$ should be flexible enough to accommodate changes in the environment (Dudin et al., 2015). The practical analysis of BMC and how it benefits organizations includes (Osterwalder \& Pigneur, 2010):

- Clearly states and defines its unique value proposition to cater to its customers.

- Identifies market segmentation to determine its customers.

- Enlists resources required to achieve the vision, mission, and goals of the company.

- Focuses on the channels to reach prospective customers.

- Lays a foundation to maintain a strong bond with the customers and retain them.

- States the revenue generation sources. 
- Enlists the key activities to enable and run the business.

- Prioritizes the key partners that are key for business performance and its excellence.

- Determines various expenses and the cost the company has to incur for its operation.

Understanding the BMC helps management grasp the core factors that are unequivocally important for business survival. This incorporates scanning of various internal as well as external factors that would impact business performance.

\section{Business Model Canvas for a Circular Economy}

After going through the generalized framework of BMC and its components, shown in Figure 1, a business should analyze the circular resources it has and define a circular business model canvas. Lewandowski (2016) applied the revised business model canvas adding the TakeBack System and Adoption Factor into the canvas, making it more relevant in including $C E$ principles. Figure 2 illustrates the circular BMC, as discussed by Lewandowski (2016). As seen in Figure 2, each segment of the canvas circular and sustainable business activities are indicated. The changing market preferences often necessitate a business redefine and reframe its business model; management would need to be open to incorporate these changes in their BMC. Figure 2 shows a brief description of key segments of a circular BMC.

Partners. No single company can solve the entire problem created by the excessive resource consumption in the linear economy. Partnership among stakeholders assures longterm balanced growth and having partners throughout the supply chain serves an important role in circular activities (Helias, 2018). A company, if lacking resources or specialization, could outsource tasks from its key partners, either domestically or internationally.

Key Activities. Lewandowski (2016) states tasks that create, offer, and deliver value proposition are key activities in any business model. A business intending to have a circular modality should have a clear understanding of critical events crucial for the organization to come across the market expectation in terms of circular products. For example, these critical activities could be related to resource efficiency, productivity enhancement, or renewable energies. Companies considering transitioning into the CE could analyze their structure to determine if any element of digitization is possible to limit resources used (Antikainen et al., 2018).

Key Resources. CE focuses on fairtrade practices, which is the ethical and responsible treatment of the stakeholders involved in the value chain (Shoenthal, 2018). It promotes the sustainable use of resources. A business should recognize the resources deemed necessary for its transition. They will require circular products that have been created through the 3R approach, use of closed-loop products-products that focus on resource lifeextension strategies, and emphasize supportive environment products (TUDelft, n.d.).

Value Proportion. Circular products and services should be perceived as beneficial by the customer. An awareness of the market towards circular products plays a crucial role in the acceptance of circular products, but as per Upadhayay and Alqassimi (2019), the general public and organizations are still unaware of CE and its importance to attaining economical, ecological and social benefits. On the one hand, it could be a challenge for business entities to convince the market of the need for circular products and its benefits. On the other hand, circular products present an opportunity for investment in new circular domains and could bring competitive advantage (Suomi \& Savola, 2019). The circular model could be proven beneficial if a company provides a quality product at a competitive price, preserving the natural stocks for ecological balance and if the company creates jobs in local communities (BNP Paribas, 2016; EMF, 2013). Circular products through resource sharing principles and product as a service (PSS) models increase accessibility of products in the market at a competitive price.

Customer Relationship. A healthy relationship with customers supports the implementation of circular models. Positive relationships enhance consumer receptiveness to company offers; whereas, an unsupportive relationship could cause market hostility. 
Segmenting customers based on demographic, social, economic, and environmental domains would help a business to classify and differentiate circular products as the customers' preferences are often impacted by these parameters. Chamberlin and Boks (2018) concluded that contamination/disgust/newness, convenience/availability, ownership, cost/financial incentive/tangible value, environmental impact, brand image/design/intangible value, quality/performance, customer service/supportive relationships, warranty and peer testimonials/reviews are factors that are important to consider for marketing circular products.

Channel. The circular economy emphasizes economization and resource efficiency (EMF, 2014). Dematerialization, the process of replacing physical things with digital alternatives, supports customization and resource-saving (Lacy, 2015). Virtualization, the process of creating virtual products, supports CE due to a lack of wasted resources (Antikainen et al., 2018). Virtualization not only saves resources, but it also provides products and services promptly. CE focuses on the use of channels which can reduce extensive use of resources and emphasizes the optimization of the existing resources.

Customer. As the core of circular products revolves around customers, understanding customers is pivotal. All segments of the circular BMC should align with customer preferences and their expectations. Biddle (1993) identifies apparent market skepticism for recycled products, and Howard (2018) states that businesses should be able to debunk the myth that recycled products are of less quality. Business should assess the level of customer awareness and their preference/perception towards the circular products. If the customers are not aware, they might end up thinking the recycled products are of less quality.

Cost. Cost is a major determining factor of the transition into a circular model. The circular business could necessitate high upfront costs, which is one of the most pressing barriers hindering progress in the circular economy (Kirchher et al., 2018). A firm should assess the transition cost and determine the best possible alternatives. These costs could include acquiring circular knowledge, technologies, supply chain redesign, process and product redesigning. By reducing the waste throughout the value chain and using circular inputs, companies can create supply chain efficiencies, which in turn, would save costs (Riel, 2018). Michal Porter's value chain strategy tool can be used to differentiate the primary and supporting activities deemed necessary for circular transition. In doing so, a company could invest in the critical factors crucial for GPT.

Revenue. A company should have clear circular business models in place to generate revenue. Businesses can choose between circular modalities such as the circular supplies model, resource recovery model, product life extension model, sharing platform, or product as a service model (Riel, 2018). Lack of precise models to generate revenue may not perpetuate the company's survival.

Take back system adoption factor. CE focuses on the close loop strategy; it optimizes the value of products by extending usage rather than disposing of them. After the end of life, products are brought back to the producer, which then, dependent upon the condition of the returned products, are reused, refurbished, remanufactured, or recycled as per Walter Stahel's Inertia Principle (Hollander et al., 2017). A business could set up multiple modalities to bring its products back after its end-of-life. It could use its existing sales channel, have direct contact with the customers, or outsource third-party vendors for product collection. All businesses might not have the opportunity or resources to adopt circularity. The level of resources, knowledge, expertise, market receptivity, and the government support will determine the capacity of a business to transition to circular modality.

The CE, which focuses on the take-make-reuse model, is different from LE, which emphasizes the take-make-dispose strategy (EMF, 2015b). The differences between a linear and circular economy can be seen with the BMC. The process of asserting nine core components of $B M C$ for $C E$ is different than the process for LE (see Figure 1 and Figure 2). For example, while circularly inclined companies may use renewal energies, 
recycle materials, and focus on multiple resource life extension strategies, these activities could be silent in the context of linearly inclined businesses. Hence, the analysis of BMC in the context of CE will help management to access their readiness to transition from a linear to a circular model of $\mathrm{P} \& \mathrm{C}$.

\section{Understanding Value Hill and Circular Strategies}

After the completion and understanding of the BMC (first step in the three-step process), the second step will involve understanding and enlisting circular activities along the Value Hill diagram.

\section{Understanding the Value Hill}

A Value Hill diagram is a circular strategy tool that dissects business activities into three core circular domains- uphill, tophill, and downhill (Achterberg et al., 2016). Each of these domains has unique circular characteristics; a business entity could incorporate circular strategies by choosing any of the circular strategies on the basis of resources it has. Figure 3 shows the differences in circular strategies between the linear and circular models through a Value Hill diagram.

In both cases, up hilling (per-use) adds value to the raw material, and the plateau (tophill) is the highest level of the value obtained from a product. The downhill (post-use) manifests the destruction of the previously built value. The difference seen is that the product use duration in the case of CE (right) is higher, and various CE measures are incorporated to retain the product's value while it drops down the hills.

In the case of the linear Value Hill (left), once the components are extracted, they are used, and after the end-of-product life, they are either landfilled or incinerated. Whereas, in the circular Value Hill (right), circular philosophy entails greater product use duration, as shown by the tophill. Contrary to the linear Value Hill, during the downhill phase, rather than ending the life of the products or the components, it incorporates circular strategies to loop the resources back to the P\&C cycle. The awareness and understanding of the Value Hill circular tool should help business entities to define their circular strategies across the hill.

\section{Phases on the Value Hill}

Understanding and positioning circular strategies across the Value Hill would help business entities to implement a circular model. The implementation of CE requires resources, financial as well as non-financial. Depending upon the resources and expertise available, a business entity could run a due diligence audit of its business to implement circular strategies across the product life cycle. Figure 4 illustrates multiple circular options across the Value Hill, namely circular design, optimal use, value recovery, and network organization (Fischer \& Achterberg, 2016).

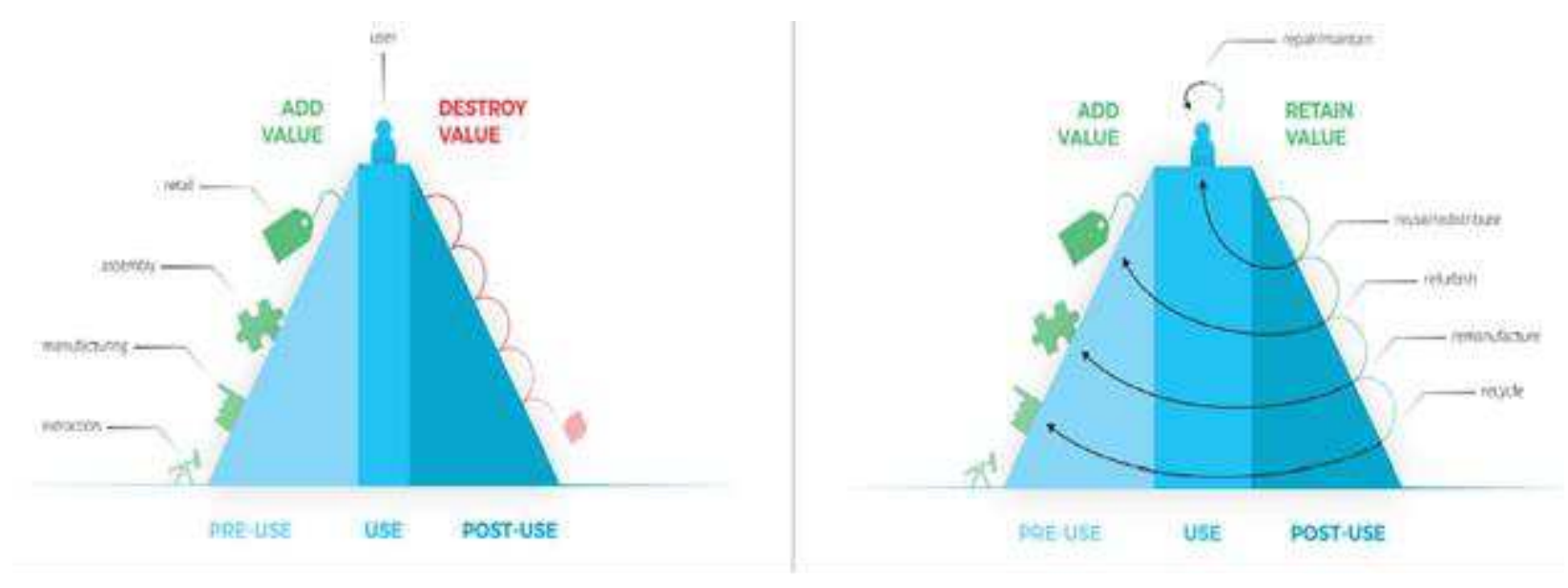

Figure 3. Value Hill Diagram Showing the Difference Between Linear and Circular Strategy.

Note. Adopted from Achterberg, Hinfelaar, \& Bocken, Master circular business with the value hill (2016).

The Value Hill on the left side represents a linear model and the Value Hill on the right represents a circular model. 

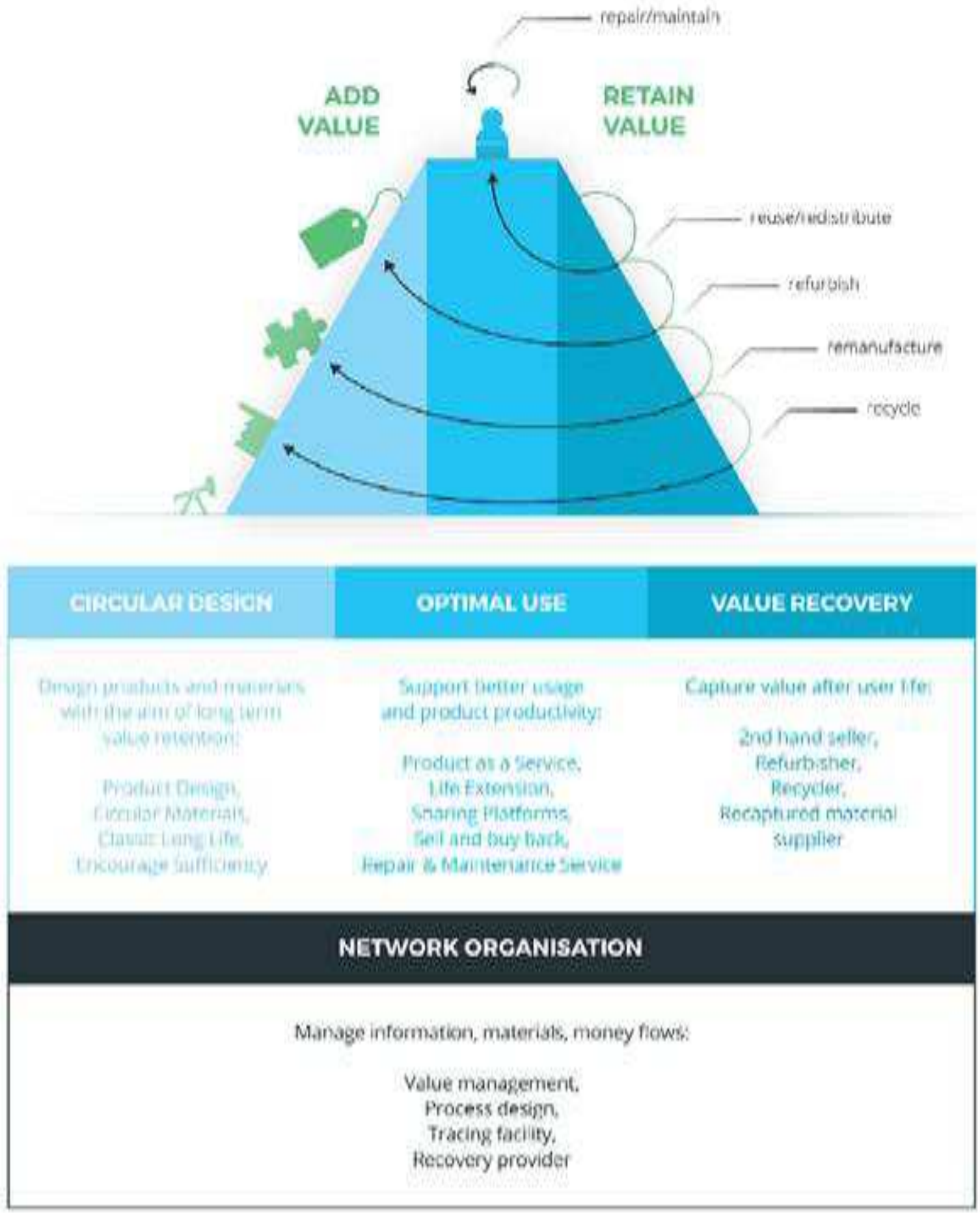

Figure 4. Value Hill Diagram Illustrating Circular Strategies.

Note: Adopted from Achterberg, Hinfelaar, \& Bocken, Master circular business with the value hill (2016). This figure demonstrates the summary of Value Hill diagram and list of circular strategies at each phase. 
Uphill Stage and Circular Design. The first stage of the Value Hill diagram is the uphill phase; in this phase, the business defines its design strategies for its product creation or the service delivery and works accordingly. The raw materials are extracted and sent to the manufacturing plant for production. After, they are assembled to be a finished product, which ultimately arrives at the market for final consumption. A business entity could incorporate the circular principle in this phase. Rather than waiting for the waste to be created and then refurbished, recycled, or reused, CE emphasizes the effective implementation of circular design from the initial phase of P\&C (Upadhayay, 2019).

Tophill Stage and Optimal Use. In this stage, the product or the service reaches the market for consumption. Figure 3 shows the difference in the tophill stage across the linear and circular models. The product utility phase is lesser in LE in comparison to CE. The linear economy persuades economics of scale through mass production, which leads to products with a short-term life cycle; this has implications on the existing stock of resources, which is already in a deficit. But on the contrary, the CE provides numerous circular business options, like easy repair and maintenance and easy to maintain modular parts which helps to extend the use period of the products through resource lifeextension strategies (RLES).

Downhill and Value Recovery. A CE focuses on the close loop strategy where the maximum possible efforts are incorporated to increase the value of products/components by keeping them in the P\&C cycle. Stahel (2010) explained the concept as a close loop strategy (as cited by Bocken et al., 2016), which stresses the reentering of products/components to the P\&C cycle. Numerous circular options (reuse, refurbish, remanufacture, or recycle) are considered in this stage, as shown in Figure 4.

Network Organization. The successful implementation of CE requires cooperation and collaboration across industries (FinanCE, 2016). CE focuses on integrating the circular principles across the supply chain. The circular gap could be an opportunity only if a business can achieve the network advantage across its supply chain (Achterberg et al., 2016). Hence an organization should evaluate the level of relationship it has with its key partners. Networking plays a crucial role in closing the resource loops; for example, for the successful implementation of reverse logistics, a company should have a good hold on market channels and its intermediaries. The network organizations could be private, public, or jointly owned.

\section{Circular Strategies Across the Value Hill}

Depending upon the state of the resources a company has, they can plot themselves along the Value Hill diagram. Some companies may focus on embedding circular strategies in the initial phase of product design; some may work to manifest CE principles during the product use period, and some may do such during the post-production stages. These strategies are not mutually exclusive and could be practiced throughout the product life cycle. A shift from a linear to a circular economy reduces the need for primary raw material, reduces the amount of waste to landfills, extends the life cycle of resources, and revalorizes the products and resources at the end of life (Bianchini et al., 2019). Table 1 summarizes the circular strategies as put forth by Achterberg et al. (2016) that could be adopted by an organization.

Table 1 lists the circular strategies a business entity can select across the phases. The circular activities defined in the Value Hill tool for the uphill phase is stated as a circular design. A circular design would be the most effective circular approach as it identifies the circular business model before it has committed resources for the P\&C. It is of advantage for a business to integrate circular economy in the new product development process (Pinheiro et al., 2019). Adding at this stage would help circular principles to be implemented in the beginning of the product development course. Furthermore, a company can design its products and process in a way where it would last for a longer duration. Here, the circular strategies are planned for the overall product life cycle, including easy maintenance, repair, and availability of accessories. These strategies are determined during the design phase to enhance duration in the consumption loop. This phase focuses on the 
use of circular materials, such as renewable energies, recyclable materials, and ethical and responsible operating practices.

Fairphone, the European Union based world-first modular smartphone has been working with this ethos (EMF, 2018). The company provides easy access to the repair and maintenance of its mobile phone so that the product use and retention ratio by the buyer increases. Mud Jeans, an apparel company, based in The Netherlands, has incorporated circular principle from the beginning in product/service design phase, the clients can rent the organic Jeans with the monthly subscription price. The ownership of the jeans is retained by the company which later would support easy reverse logistic and recyclability (EMF, n.d.). Both of these companies have incorporated circular options from the product design phases.

For the tophill, which is the product use period, the optimal use strategy is adopted. At this point, a business will look for circular options, which would increase the value of the product while it is in use. Where the uphill focuses on circular options during the design phase, the tophill focuses on using those options to ensure that the product consumption period is extended. It includes circular strategies like easy availability and accessibility to the repair and maintenance components, tools, and guidelines as listed in Table 1. Fairphone comprises of four modules, if any of the components malfunction, rather than purchasing a new phone set, the company provides an option to repair and replace the specific broken module. Similarly, sharing platforms where the excess ideal unused resources are shared (Upadhayay and Alqassimi, 2018), like Uber and Airbnb, help in optimizing the use of ideal resources. Product as a Service (PSS) model where the seller maintains the ownership of the actual product and only the service is sold to the buyer also optimizes the use of the products (Stahel, 2010).

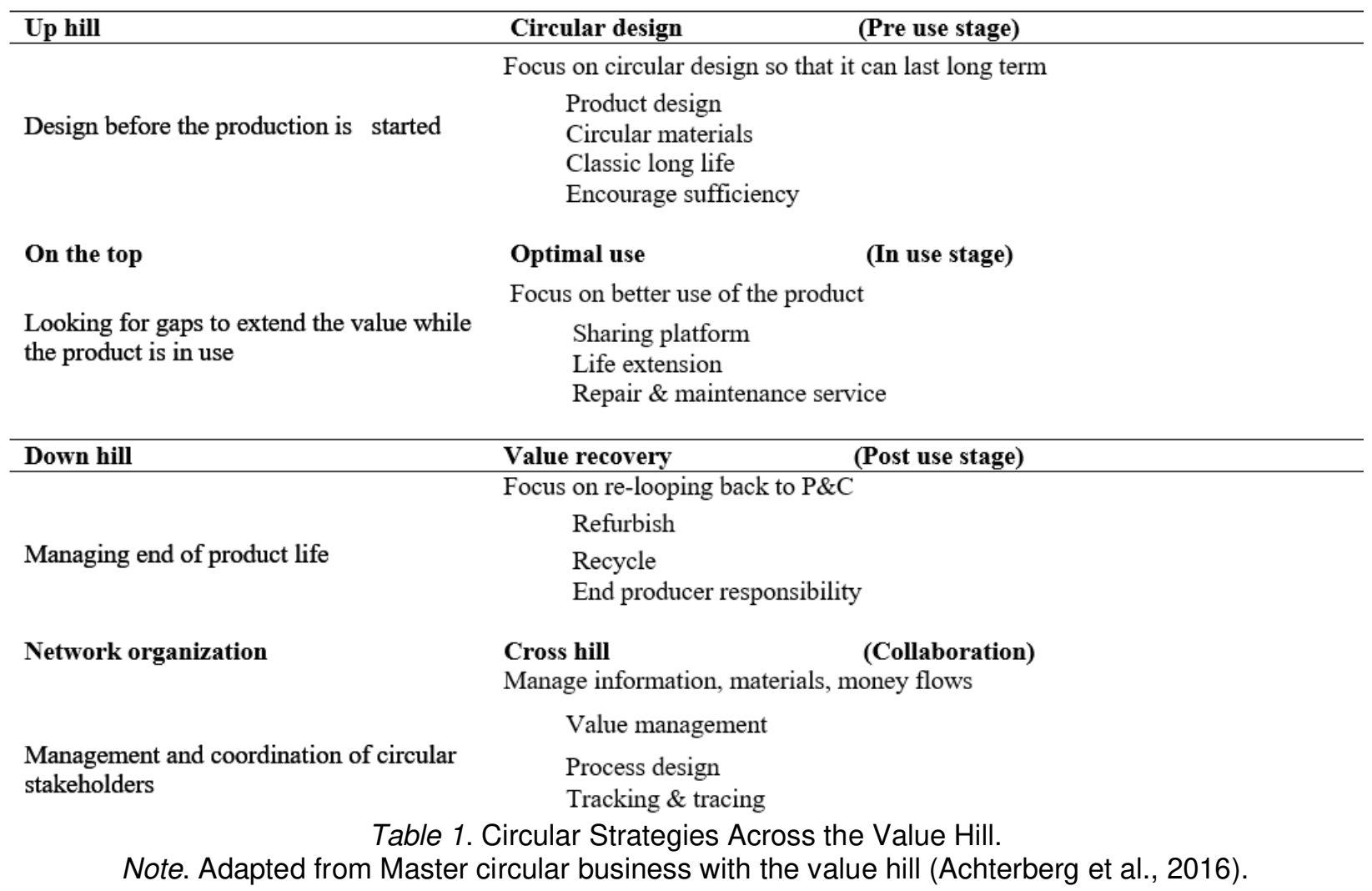




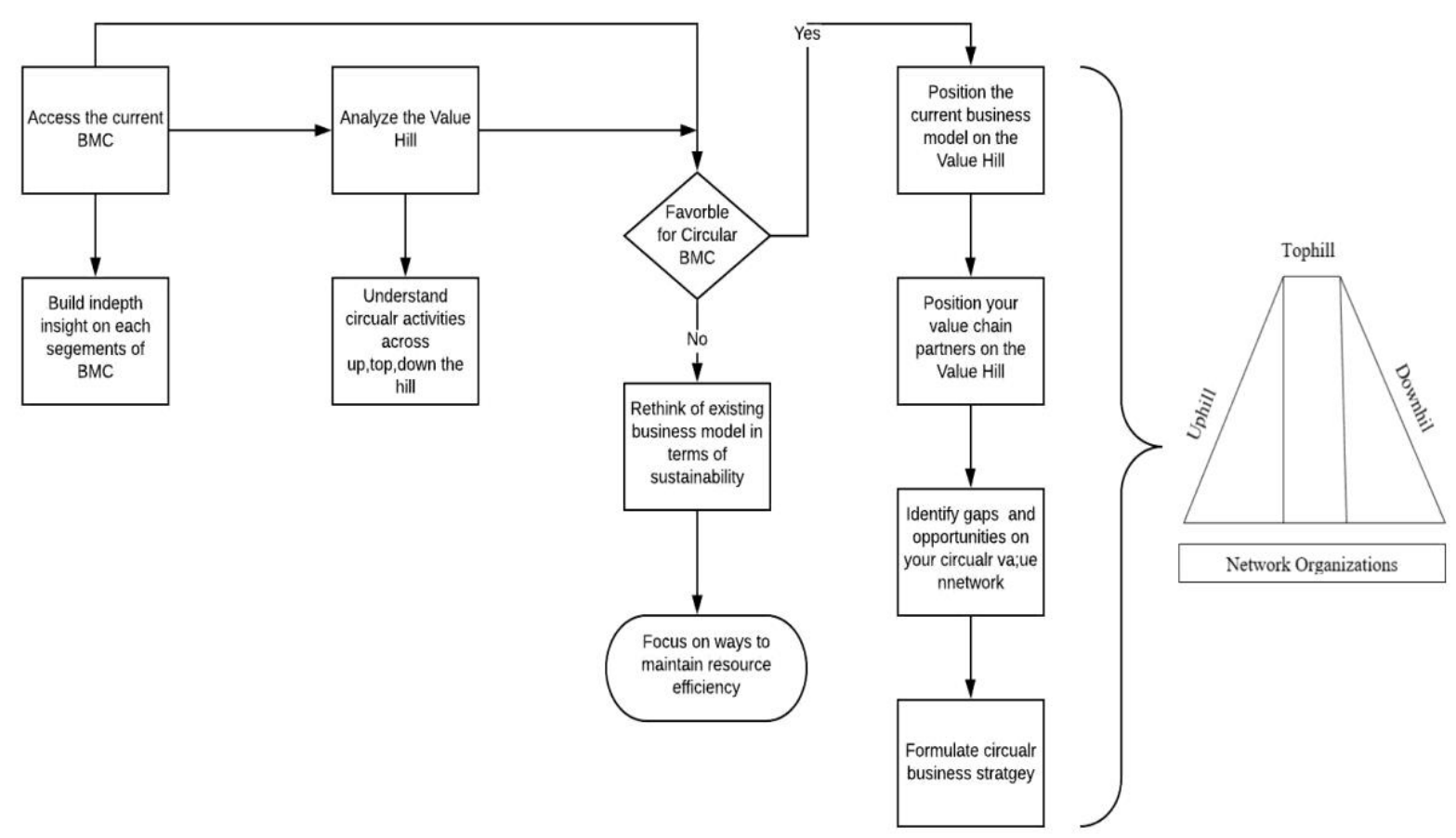

Figure 5. Steps for Accessing Circular Strategies for Business Entity.

Note: Illustration of step 1,2 and 3. Adapted from Osterwalder and Pigneur (2010), Lewandowski (2016), Achterberg et al. (2016).

Downhill is the post product use phase; in the case of the linear economy, the products after use or at the end of life are either disposed of or incinerated, but in the CE, they are looped back into the P\&C cycle to enhance the value of a product. Refurbishing, remanufacturing, and recycling methods are used to return the products back to the $\mathrm{P} \& \mathrm{C}$ cycle.

Networking has a significant effect on aligning the key partners in the business model canvas. Network Organization brings all the three phases on the Value Hill together. This is illustrated in Figure 5 and in Table 1. For example, for the successful implementation of reverse logistics, the producer should be able to bring the products back after the end of their life; similarly, there would need to be enough mature secondary market for the trading of the reused products.

\section{Framing the Circular Business Activities- Good Point for Transition}

After assessing the BMC (Step 1) and the Value Hill tool and circular strategies on Value Hill
(Step 2), a business entity should decide the best possible circular strategy that would fit their structure. Choosing this point of transition to CE is stated as Good Point for Transition which is the final step of the process (Step 3). At this stage, a company would be well aware of its strengths and weaknesses in terms of circular modalities and would be posed to make the best possible circular decisions. Five business models: circular supply chain, recovery and recycling, product life extension, sharing platform, and product as a service (PSS) have proven to be successful circular business models (Lacy, 2015). Figure 5 illustrates the overall process (Steps 1, 2, 3) a business entity could undertake to analyze its circular transition. While Step 1 and Step 2 focuses on the assessment of the circular resources and circular strategies, the Step 3 concentrates on decision making.

After completing Step 1 and Step 2 (see Figure 5), a business would reach the point where it would be necessary to decide if CE modalities were approachable and realistic for it or not. If the 
transition is achievable and beneficial, the company would reach the third and final stage of implementing circular modalities (Step 3), as shown in Figure 5. Step 3 is comprised of four sub-steps as described by Achterberg et al. (2016). It starts with positioning the existing business model and the value chain partners on the Value Hill diagram, which is followed by accessing the gaps in the circular networks to to build another product, thus, from $100 \%$ surplus or recycled materials. In 2019, IKEA gave a second life to 47 million products (IKEA, n.d.). The company envisions sharing its existing business model using digital technology and launching products as a service modality (PSS) (IKEA Australia, 2018).

The product and process design phase focuses on durability, a renewable or recyclable

\section{Optimal use}

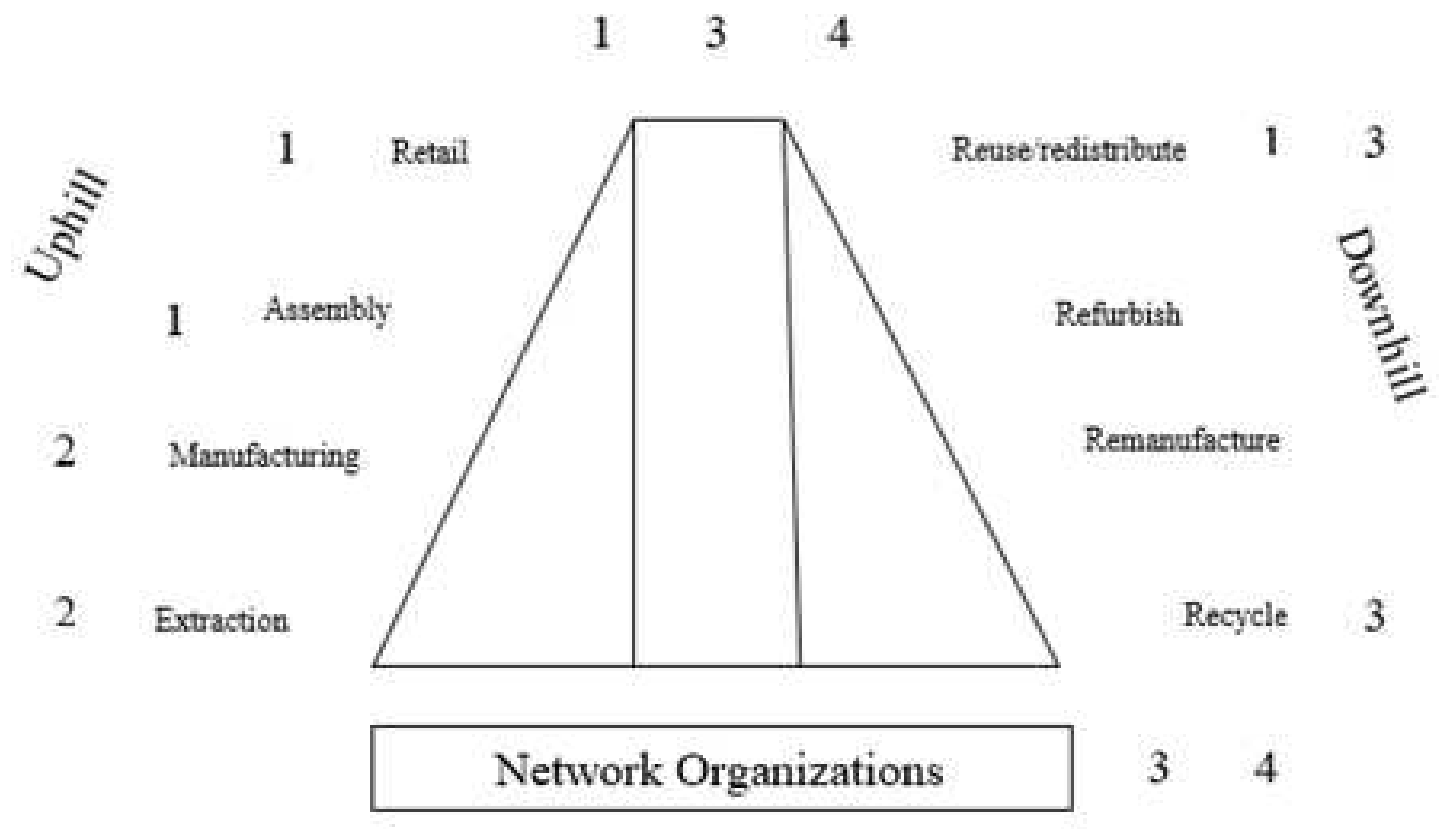

Figure 6. IKEA's Circular Strategies Across the Value Hill

Note: This figure illustrates existing and expected circular strategies adopted by IKEA along with the Value Hill diagram. Digits 1,2,3 and 4 represents each sub-step included in step 3.

formulate the new circular business strategy.

For practicality and better understanding, IKEA, the multi-national furniture and fixture selling company, is considered. The company was established in 1943. By 2030, IKEA aims for $100 \%$ circular products through recycled, remanufactured, refurbished, and reused products. The company has vowed to collaborate with other organizations to promote a circular economy (IKEA, n.d.). The company specializes in designing and manufacturing modular products which facilitate easy repair and is looking for ways to use the leftovers from one production process material, minimum waste creation, standardization, adaptability, easy care and repair, easy disassembly and reassembly and emotional attachment to products (IKEA Australia, 2018). IKEA Australia has also started the take-back program for certain products. All of these factors could be resembled across the nine generic segments of BMC, as shown in Figure 1, and eleven segments of circular BMC, as illustrated in Figure 2. Though currently running in a linear model, IKEA is also adapting to achieve its circular vision by 2030 . Considering Achterberg et al.'s (2016) guidelines for assessing circularity, Figure 6 highlights the 
circular strategies IKEA uses across the Value Hill diagram; each of the numbers stated on the Value Hill diagram identifies the sub-steps for Step 3.

Furthermore, Step 3 comprises of four consecutive steps (see Figure 5) to incorporate circular strategies which are based on the previous Steps, 1 and 2. At this stage in Step 3, a business would decide whether to invest in the circular gap or opportunity or not. It can be inferred that one circular decision could have multiple impacts on other phases. For example, a modular design decided during the uphill phase would have an impact on product utilization (through easy repair and long life), and value recovery (through easy dissembling for reuse, remanufacture or recycle). The following information identifies and assesses IKEA's transition to a circular modality along with recommendations for successful implementation.

\section{Step 3, Sub-Step 1: Position the Current Business Model on the Value Hill}

The first step encompasses determining where the existing business model lies in the Value Hill tool. Currently, IKEA designs, manufactures, and retails its modular products (uphill phase; see digit 1 on Figure 6). Modular products are easy to repair, reuse, and recycle (downhill phase; impact of circular design on value recovery), and this leads to higher product utilization since customers would be able to repair the products rather than replace them, ultimately, leading to an increase in the life of furniture and fixtures (tophill phase; impact of circular design on optimal utilization). Additionally, IKEA started take-back schemes (IKEA Australia, 2018). This would also have an impact on the value recovery (phase: downhill; see digit 1 on the Value Hill diagram). The company is moving towards the use of sustainable products (uphill), including recycled woods and ethically produced cotton (Nini, 2018).

\section{Step 3, Sub-Step 2: Position your Value Chain Partner on the Value Hill}

The circular transactions could not be done in isolation; the business needs to coordinate and collaborate with its value chain partners. IKEA is working closely with its supply chain partners, non-governmental organization
(NGO) and United Nations (UN) bodies to become people and planet positive (IKEA, 2014). IKEA has made Universal Trade Zone (UTZ) certification mandatory for all the coffee and tea they serve in IKEA restaurants, as well as the Marine Stewardship Council (MSC) and Aquaculture Stewardship Council (ASC) certifications mandatory for the seafood. These certifications guarantee that the suppliers are using sustainably manufactured/extracted products (phase: uphill; see digit 2 on Figure 6). These steps influence the product design phase for IKEA.

\section{Step 3, Sub-Step 3: Identify the Gaps or Opportunities on Your Circular Value Network}

After auditing the level of circular business involvement and supply chain cooperation for the circular business, a company would identify the gaps of opportunity. Currently, upon being sold, IKEA loses ownership of its products. Thus, the products may be disposed of after the end of its life by the buyer. This leads to a loss of valuable resources and technologies (loss during the downhill as no circular activities are possible) and does not allow the company to recycle and reuse the products (loss during the downhill), or extend the life of its existing products (loss during the tophill). In fact, there is still a lack of cooperation and collaboration across the supply chain for IKEA (immature network organization). These gaps are shown in Figure 6 with digit 3 . The gaps are present across uphill, tophill, downhill and network organizations.

\section{Step 3, Sub-Step 4: Formulate Circular Business Strategy}

Though IKEA has implemented various circular business modalities, there are still numerous circular ventures left to be explored. Administering products as a service modality (PSS) would be a circular option (proposed circular strategies for this case). PSS is a business model based on the circular principle where the company, rather than selling the product, sells the service that would come from the product, and ultimately, holds the ownership on the product (see Stahel (2010) for Performance Economy and PSS). This circular business model should also be supported by efficient reverse logistics, which helps in getting 
the products back to IKEA (network organization; see digit 4 on Figure 6). The successful implementation of PSS would allow IKEA to reuse, remanufacture and recycle products after the end of their life.

Thus, IKEA has been working on the ethos of CE. Though the company has inducted numerous circular strategies, still it has not been able to incorporate the close loop strategy one hundred percent. In a close loop strategy, the products/components are reversed back to the existing or new $\mathrm{P} \& \mathrm{C}$ cycle so that the life/value of product/component is enhanced. On the basis of the resources IKEA and its value chain partners have, PSS could be one of the circular strategies to be implemented. The circular strategies bring environmental, economic, and social benefits.

\section{Recommendations}

Though transition from a linear model to a circular model of P\&C has numerous social, economic and ecological benefits, this shift could be challenging as the transition often requires a paradigm shift throughout the life of a product, i.e. designing, operation, production, marketing and end of life. Further, since all companies might not have all the resources required for this shift, the GPT may differ. Hence, the following actions are recommended.

- A business should assess its business model canvas to determine its stock of circular resources, expertise and economic relevance of the circular model for the company. In fact, economic viability is the most pressing requirement for businesses to adopt CE (Kirchherr et al., 2017). Businesses would need to be confident that the transition to a circular modality would be lucrative.

- Further, circularity requires cooperation and collaboration across the supply chain (European Environment Agency, 2016). A company should place itself and its supply chain partners across the Value Hill diagram to analyze and identify the value generating circular strategies.

- A company could also choose to transition incrementally rather than make radical circular changes. In doing so, businesses could reduce the inherited circular risks as not all circular models equate to profits for all companies.

- Those companies for whom transition to CE is not feasible under the current circumstances of resources availability could focus on resources conserving business operation practices such as using renewal sources of energies and using recyclable and reusable products from suppliers.

\section{Conclusion}

To fill the confusion and gap prevalent when it comes to deciding to transition from a linear to a circular economy, this review paper elucidates a three-step process that would help a business to decide if a circular transition is of benefit through analysis of circular resources, expertise, and value chain partners. This study has highlighted the importance of understanding and assessing the current business activities through business model canvas (BMC) and reconciling these activities along and across the Value Hill diagram to come up with circular business strategies that fit best with an organization.

Since each company is unique in terms of their resources, expertise, and circular activities, the choice of achieving GPT may also differ amongst businesses. A business may focus on uphill, tophill or downhill circular strategies as defined by the Value Hill diagram. Those which focus on the uphill are more concerned with the circular product design; those on the tophill are inclined to optimum product utilization mechanism and those companies which emphasize the downhill are oriented towards resource value recovery modalities. Equally important, the presence of effective circular networks would make the transition from LE to $\mathrm{CE}$ easier. Even though this paper is a generic study to assist companies willing to shift to a circular model of $\mathrm{P} \& \mathrm{C}$, these generic steps could be applied and tested across industries in the future. The transition from a linear to a circular model has become a mandate for a sustainable future and business entities will play a prominent role in achieving this exuberance economy by balancing people, the planet and profit. 


\section{References}

Achterberg, E., Hinfelaar, J., \& Bocken, N. (2016). Master circular business with the value hill. Circle Economy.

Antikainen, M., Uusitalo, T., \& Kivikyto-Reponen, P. (2018). Digitalization as an enabler of circular economy. ScienceDirect, 45-49. https://doi.org/10.1016/i.procir.2018.04.027

Bianchini, A., Rossi, J., \& Pellegrini, M. (2019). Overcoming the main barriers of circular economy implementation through a new visualization tool for circular business models. Sustainability, 11(6614), 1-33. https://doi.org/10.3390/su11236614

Biddle, D. (1993). Recycling for profit: The new green business frontier. Harvard Business Review. https://hbr.org/1993/11/recycling-forprofit-the-new-green-business-frontier

BNP Paribas. (2016, April 10). The circular economy: Creating new jobs. https://group.bnpparibas/en/news/circulareconomy-creating-jobs

Bocken, N. M., Pauw, I. d., Baakker, C., \& Grinten, B. V (2016). Product design and business model strategies for a circular economy. Journal of Industrial and Production Engineering, 33(5), 308-320. http://dx.doi.org/10.1080/21681015.2016.11721

\section{4}

Bocken, N., Miller, K., \& Evans, S. (2016, June 16-17). Assessing the environmental impact of new circular business models [Conference session]. Conference "New Business Models"Exploring a Changing View on Organizing Value Creation, Toulouse, France. https://www.researchgate.net/publication/30526 4490 Assessing the environmental impact of new Circular business models

Boll, C. R. (2018, February 22). Ride sharing is already reducing car ownership and public transportation usage. https://www.foley.com/en/insights/publications/2 018/02/ride-sharing-is already-reducing-carownership-and

Chamberlin, L., \& Boks, C. (2018). Marketing approaches for a circular economy: Using design frameworks to interpret online communications. Sustainability, 10(6). http://dx.doi.org/10.3390/su10062070

Ching, H. Y., \& Fauvel, C. (2013). Criticisms, variations and experiences with business model canvas. European Journal of Agriculture and Forestry Research, 1(2), 26-37.

Circular Economy. (2020). The circularity gap report 2020.

https://pacecircular.org/sites/default/files/202001/Circularity\%20Gap\%20Report\%202020.pdf

Circular economy: Critics and challenges. (n.d.). Circular Academy. http://www.circular.academy/circular-economycritics-and-challenges/

Dudin, M. N., Lyasnikov, N. V., Leont' eva, L. S., Reshetov, K. J., \& Sidorenko, V. N. (2015). Business model canvas as a basis for the competitive advantage of enterprise structures in the industrial agriculture. Biosciences Biotechnology Research Asia, 12(1), 887-894.

Ellen MacArthur Foundation (EMF). (2015a). Growth within: A circular economy vision for a competitive

Europe.

https://www.ellenmacarthurfoundation.org/asset s/downloads/publications/EllenMacArthurFound ation Growth-Within July15.pdf.

Ellen MacArthur Foundation (EMF). (2015b). Towards a circular economy: Business rationale for an accelerated transition. https://www.ellenmacarthurfoundation.org/asset s/downloads/TCE Ellen-MacArthurFoundation 9-Dec-2015.pdf.

Ellen MacArthur Foundation. (2017, May 31). Groupe Renault renews commitment to the circular economy. https://www.ellenmacarthurfoundation.org/news/ groupe-renault-renew-their-commitment-to-thecircular-economy.

Ellen MacArthur Foundation. (2018). Circular consumer electronics: An initial exploration. https://www.ellenmacarthurfoundation.org/asset s/downloads/Circular-Consumer-ElectronicsFV.pdf

Ellen MacArthur Foundation. (n.d.). Pioneering a lease model for organic cotton jeans. 
https://www.ellenmacarthurfoundation.org/casestudies/pioneering-a-lease-model-for-organiccotton-jeans

EMF Ellen MacArthur Foundation. (2014). Towards the circular economy. Accelerating the scale-up across supply chains. http://www3.weforum.org/docs/WEF ENV Towa rdsCircularEconomy Report 2014.pdf

European Environment Agency. (2016). Circular Economy in Europe. Developing the knowledge base. EEA Report No2/2016.

European Parliament. (2018, April 10). Circular economy: definition, importance and benefits. https://www.europarl.europa.eu/news/en/headlin es/economy/20151201STO05603/circulareconomy-definition-importance-andbenefits\#: :text=Moving\%20towards $\% 20 \mathrm{a} \% 20 \mathrm{~m}$ ore\%20circular,jobs\%20in\%20the\%20EU\%20al one)

Money makes the world go round (2016).FinanCE.

https://circulareconomy.europa.eu/platform/sites/ default/files/knowledge -

money makes the world go round.pdf

Fischer, A., \& Achterberg, E. (2016). Create a financeable circular business in 10 steps. Sustainable Finance Lab, Circular Economy and Nederland Circulair!

Geng, Y., \& Doberstein, B. (2008). Developing the circular economy in China: Challenges and opportunities for achieving 'leapfrog development'. International Journal of Sustainable Development and World Ecology, 15, 231-239. http://dx.doi.org/ 10.3843/SusDev.15.3:6

Ghisellini, P., Cialani, C., \& Ulgiati, S. (2016). A review on circular economy: The expected transition to a balanced interplay of environmental and economic systems. Journal of Cleaner Production, 114, 11-32. https://doi.org/10.1016/j.jclepro.2015.09.007.

Helias, V. (2018, January 15). Why the future of consumption is circular. https://www.weforum.org/agenda/2018/01/future -consumption-circular-economy-sustainable/
Hollander, M. C., Bakker, C. A., \& Hultink, E. J. (2017). Product design in a circular economy: Development of typology of key concepts and terms. Journal of Industrial Ecology, 21(3). http://doi.org/10.1111/jiec.12610

Howard, B. C. (2018, April 20). Five myths about recycling.

https://www.washingtonpost.com/outlook/fivemyths/five-myths-aboutrecycling/2018/04/20/9971de66-43e6-11e88569-26fda6b404c7 story.html.

IKEA. (2014). People \& planet positive. IKEA group sustainability strategy for 2020. https://www.ikea.com/ms/en AU/pdf/reportsdownloads/sustainability-strategy-people-andplanet-positive.pdf.

IKEA Australia. (2018). People and planet positive 2018: Creating a circular IKEA. https://www.ikea.com/ms/en AU/pdf/reportsdownloads/sustainability-strategy-people-andplanet-positive.pdf.

IKEA. (n.d.). A circular IKEA - making the things we love last longer. https://www.ikea.com/us/en/this-isikea/sustainable-everyday/a-circular-ikeamaking-the-things-we-love-last-longerpub9750dd90

Kirchher, J., Piscicelli, L., Bour, R., KostenseSmit, E., Muller, J., Huibrechtse-Truijens, A., \& Hekkert, M. (2018). Barriers to the circular economy: Evidence from the European Union (EU). Ecological Economics, 150, 264-272.

Kirchherr, J., Reike, D., \& Hekkert, M. (2017). Conceptualizing the circular economy: An analysis of 114 definitions. Resources, Conservation \& Recycling, 127, 221-232.

Lacy, P., Long, J., \& Spindler, W. (2020, January 20). How can businesses accelerate the transition to a circular economy? https://www.weforum.org/agenda/2020/01/howcan-we-accelerate-the-transition-to-a-circulareconomy/

Lewandowski, M. (2016). Designing the business models for circular economy- Towards the conceptual framework. Sustainability. 
Murray, A., Skene, K., \& Haynes, K. (2017). The circular economy: An interdisciplinary exploration of the concept and application in a global context. Journal of Business Ethics, 140(3), 369-380. http://doi.org/10.1007/s10551-015-2693-2

Osterwalder, A., \& Pigneur, Y. (2010). Business model generation. John Wily \& Sons, Inc.

Pinheiro, M. A., Seles, B. R., Fiorino, P. D., Jugend, D., Jabbour, A. B., Silva, H. M., \& Latan, $H$. (2019). The role of new product development in underpinning the circular economy: A systematic review and integrative framework. Management Decision, 57(4), 840-862. https://doi.org/10.1108/MD-07-2018-0782

Riel, A. V. (2018, November 2). How the circular economy unlocks new revenue streams. https://www.greenbiz.com/article/how-circulareconomy-unlocks-new-revenuestreams\#: :text=\%22By\%20reducing\%20waste \%20and\%20using,customers\%2C\%22\%20van \%20Dun\%20said.\&text=Under\%20the\%20Produ ct\%20Lifecycle\%20Extension, generating\%20ad ditional\%20revenue\%20fro

Shoenthal, A. (2018, December 14). What exactly is fair trade, and why should we care? https://www.forbes.com/sites/amyschoenberger/ 2018/12/14/what-exactly-is-fair-trade-and-whyshould-we-care/\#1356a80b7894

Schut, E., Crielaard, M., \& Mesman, M. (2015). Circular economy in the Dutch construction sector. A perspective for the market and government. Riskswaterstaat. Ministry of Infrastructure and the Environment.

Stahel, W. R. (2010). Performance economy (2nd ed.). Palgrave Macmillian.

Suomi, O., \& Savola, T. (2019, Feburary 25). Circular economy brings competitive advantage to companies.

https://www.businessfinland.fi/en/whatsnew/blogs/2019/circular-economy-brings competitive-advantage-to-companies/

TUDelft. (n.d.). Circular product design. https://www.tudelft.nl/en/ide/about

ide/departments/sustainable-designengineering/research-areas/circular-productdesign/

Upadhayay, S., \& Alqassimi, O. (2019). A survey on understanding the perception and awareness towards a circular economy. A comparative study between Nepal and the USA. Westcliff International Journal of Applied Research, 3(1), 37-46.

Upadhayay, S. (2019, July 28). From a linear to a circular economy. https://kathmandupost.com/columns/2019/07/28/ from-a-linear-to-a-circular-economy

Upadhayay, S., \& Alqassimi, O. (2018). Transition from linear to circular economy. Westcliff International Journal of Applied Research, 2(2), 62-74. https://www.westcliff.edu/wpcontent/uploads/2019/08/ Anonymous-201822.pdf. 